Western University

Scholarship@Western

Aboriginal Policy Research Consortium International (APRCi)

8-2011

\title{
Postcolonial Transformation of the Australian Indigenous Population
}

John Taylor

Follow this and additional works at: https://ir.lib.uwo.ca/aprci

Part of the Other Geography Commons

Citation of this paper:

Taylor, John, "Postcolonial Transformation of the Australian Indigenous Population" (2011). Aboriginal Policy Research Consortium International (APRCi). 351.

https://ir.lib.uwo.ca/aprci/351 


\title{
Postcolonial Transformation of the Australian Indigenous Population
}

\author{
JOHN TAYLOR \\ Centre for Aboriginal Economic Policy Research, The Australian National University, Canberra, \\ ACT 0200.Email: j.taylor@anu.edu.au
}

Received 21 December 2010; Revised 17 March 2011; Accepted 28 March 2011

\begin{abstract}
The 1967 constitutional referendum paved the way for the application of a single national methodology for the construction of a self-identified Indigenous population via census, survey, and administrative data collection and these sources have provided for statistically meaningful official estimates of Indigenous population growth and spatial redistribution as well as for some understanding of the dynamics underpinning change. The primary purpose of this paper is to outline the course of this change and to reflect on matters arising that are of concern and interest to public debate on population growth and its implications. To do this meaningfully it is necessary first to gain an appreciation of what is referred to as 'postcolonial demography'. This term encapsulates the post-referendum acquisition of official population data involving the construction of Indigenous population as simply the minority half of a statistical binary. While these data provide for an analysis of growth and change in an aggregate Indigenous population, and while the product continues to play a key role in Indigenous-state relations, we remain pressed to articulate the geography of Indigenous peoples' sociality amidst growing demands to do so.
\end{abstract}

KEY WORDS postcolonial demography; Indigenous population; population geography

\section{Introduction}

The precise size, composition, and distribution of the Aboriginal and Torres Strait Islander populations of Australia are unknown, and probably unknowable. This is because compiling a statistical profile is not straightforward. Far from being a set of observable 'facts' it derives from an interplay between changing political, administrative, and cultural processes: in particular, the manner in which governments attempt to enumerate Indigenous peoples and the choices made by respondents to such overtures (Rowse, 2006). What we can say, however, is that the population revealed by these processes at any one time is almost certainly a minimal estimate of the descendants of the first Australians.
According to the Australian Bureau of Statistics (ABS, 2009a), the current (2011) Indigenous population is estimated to be 576000 , approximately $10 \%$ of whom would claim Torres Strait Islander origins. This population is forecast to reach 1 million by 2040 (Biddle and Taylor, 2009). While projecting this far out is speculative due to data quality issues, there is no doubt that a population of this order is inevitable soon. Significantly, this would constitute a population level in the region of those best estimated for 1788 (Mulvaney, 2002). Thus, while the size of the population may soon return to the pre-colonial level as far as this can be known, there is less doubt about the fact that in the meantime its distribution and composition has been greatly transformed. 
Outlining the course of these long-term transformations is no easy task and it is not attempted in any detail here. The main problems are a lack of consistency in defining the population over time and the lack of a consistent methodology for enumeration. Smith (1980) has documented in some detail the efforts made by colonial authorities and later the federation to count Indigenous people and he makes an admirable job of piecing together a coherent demographic history. Aside from those who were missed altogether, the overwhelming observation to emerge from the historic record concerns the unknown but large number of Indigenous people who were absorbed, statistically, into the general population as a consequence of racial politics that classified people according to 'blood quantum' (Smith, 1980; Rowse, 2006; Smith et al., forthcoming).

My focus, then, is on the contemporary period which, from a demographic perspective, commenced after the 1967 constitutional referendum. This paved the way for the application of a single national methodology for the construction of a self-identified Indigenous population via census, survey, and administrative data collection. Despite well-documented subsequent problems of census closure and variable coverage (Gray, 1997; Cunningham, 1998; Passel, 1996; Ross, 1999; Kinfu and Taylor, 2005; Hill et al. 2007), these sources have increasingly provided for statistically meaningful official estimates of Indigenous population growth and spatial redistribution as well as for some understanding of the dynamics underpinning change.

The primary purpose of this paper is to outline the course of this change and to reflect on matters arising that are of concern and interest to public debate on population growth and its implications. However, in order to do this meaningfully it is necessary first to gain an appreciation of what I call 'postcolonial demography'. This term encapsulates the post-referendum acquisition of population data as an integral part of attempts by the state at reparation for the past and present social exclusion of Indigenous peoples, but in ways that remain centralist and 'top-down' with Indigenous people viewed and treated as having little or no agency of their own (Buckmaster and Thomas, 2009).

Some attention is afforded this matter. It produces a construction of Indigenous population as simply the minority half of a statistical binary which presumes a degree of homogeneity and sense of collective identity that simply does not match Indigenous people's actual sociality and spatiality. In effect, both the assumed scale of collective identity and its composition can be found wanting. This set of assumptions produces a demographic window onto the Indigenous world that exists solely to service constitutional and legislative requirements. Scant regard is paid to the nature of Indigenous social and economic relations which, almost by definition, isolate the population in the first place. Thus, while we can observe growth and change in an aggregate Indigenous population, and while undoubtedly this plays a key role in Indigenous-state relations (Rowse, 2009), we remain far more pressed to articulate a geography of Indigenous peoples that reflects Indigenous world views and practice, a point that is increasingly recognised in Australia and other settler states (Kukutai, 2004; Morphy, 2007a; 2010a; Taylor, 2008; Pereira et al., 2009; Prout, 2009; Walling et al., 2009). We return to this issue by way of conclusion, but first, more on the subject of political demography.

\section{Postcolonial demography}

A sub-disciplinary endeavour has emerged in postcolonial Australia that, for want of a better term, has become referred to as 'Indigenous demography', mostly as a form of applied demography and population geography. This arises as part of the state project of distributive or remedial social justice that seeks to make legible the needs of particular groups, in this instance Indigenous Australians. Demography is central to this project with its focus on quantum and the calibration of change, but the underpinning is political and arises out of a view of Indigenous particularity as oppositional to the dominant society. Articulation of this view is motivated by the population binary - Indigenous/nonIndigenous - that is, generated by the administrative mechanisms alluded to above. In Australia, this binary has only reliably been available in recent times but it stems from the beginnings of colonial relations and long-standing policies of state management and control of Indigenous peoples, including over their identity (Dodson, 1994).

If we go back somewhat, we see that one of the tasks assigned to the about-to-be first Governor of New South Wales in 1787 was '... to procure an account of the numbers inhabiting the neighbourhood of the intended settlement and report your opinion to one of our Secretaries of State in what manner our intercourse with these people may be turned to the advantage of this country' 
(Phillip, 1787). Since that time, 'these people' (the Indigenous peoples of Australia) have formed a variously defined single population category (actually now a double category - Aboriginal and Torres Strait Islander - but for most demographic and broad policy analysis these tend to be combined).

In terms of tracking contemporary Indigenous population change and projecting future growth, the key event was the constitutional referendum of 1967 because this enabled the enumeration of a self-identified population binary on a consistent basis nationally for the first time, although that was not the real intention. Basically, the referendum resulted in amendment of s. 51 of the Constitution and removal of s. 127 . The first of these actions enabled the federal government to make laws specifically in relation to Indigenous people for the first time under the so-called 'race power' in s. 51 (xxvi); the second, removed the phrase, 'in reckoning the numbers of the people of the Commonwealth, or of a State, or other part of the Commonwealth, Aboriginal natives shall not be counted'. In fact, 'Aboriginal natives' had been counted, but for the purposes of then statistically excluding them, so what the referendum really enabled was for Indigenous Australians to be counted for the first time without a need to specifically identify them (Rowse, 2006, 2).

However, and this is part of the postcolonial turn, because of the amendment to s. 51 the state was now in a position to discriminate in favour of Indigenous people. Part of the case for policies and programmes to support such an approach was a need to render Indigenous people 'statistically visible' (Rowse, 2006, 5). Accordingly, the Commonwealth Statistician soon declared that the 1971 Census would include a self-identified race question, 'for general interest, and in particular to meet the statistical requirements of Commonwealth and State authorities responsible for Aboriginal Affairs' (Commonwealth Bureau of Census and Statistics, 1973, xiii). In that census, respondents could self-identify their 'racial origins' as simply Aboriginal or Torres Strait Islander and, with subsequent variation (dropping the term 'racial'), this form of question has provided a consistent basis for the construction of the state-derived population binary ever since. While these remain two distinct censusderived social groupings (despite overlap in identity), for most demographic and broad policy analysis they tend to be combined and referred to as 'Indigenous' which creates the default comparator grouping 'non-Indigenous'.
Responsibility for the task of gathering statistics on Indigenous and non-Indigenous Australians thus fell from the outset to the ABS. Methodological developments instigated by that agency to elicit population coverage began in 1971 and by the 1990s had resulted in ministerial-level agreements between federal and state governments for the adoption of a standard self-reported Indigenous status question in all official statistical collections (including in all official household surveys) as well as in a muchexpanded Indigenous-specific survey and census programme (ABS, 2007). From the state's perspective, it is these activities that now provide for reporting of progress in Indigenous affairs against a 'Closing the Gaps' strategy in which the calibration of Indigenous socioeconomic change relative to non-Indigenous outcomes plays a central accounting role (SCRGSP, 2009; Taylor, 2008).

This, then, is the essence of postcolonial demography. It stems from a view of Indigenous particularity as oppositional to the dominant society (Kowal, 2010, 189-192). Postcolonial logic requires that the representation of Indigenous sociality be relational because the aim is not to give expression and substance to Indigenous difference per se but rather to compare it (Dodson, 1994). The focus then is on information that defines the 'other' based on a legal/analytical definition of Indigenous peoples as opposed to self-definitions that are more practical/strategic (Niezen, 2003, 19). This produces frustration for Indigenous peoples because of their historical and social diversity and because the question of definition now pits analysis against identity (Niezen, 2003, 19). Thus, while we may now chart Indigenous population growth, redistribution and change in composition over several decades, and do this rather well because of a burgeoning official statistical archive (Rowse, 2006), this should be understood for what it is and what it is not.

\section{Population growth 1971-2006}

In order to meet its new requirement for Indigenous inclusion in official statistics, the ABS introduced special enumeration procedures for the 1971 Census in the Northern Territory and Western Australia with interviewer-based counting and enhanced field operations. Over time, this system has been gradually modified and geographically extended and it now constitutes a multifaceted Indigenous Enumeration Strategy as an integral part of the general census opera- 
tion. In urban areas, the strategy addresses issues arising from distrust of officials, population mobility and large households; in remote areas it is designed to take into account geographic isolation, high mobility, traditional culture, communication problems due to language, and unfamiliarity with form-filling. While these methods are now well tested and fine tuned, basic problems in the administration of field procedures and data processing still remain (Morphy, 2007b) leading to striking regional patterns of undercounting (mostly in remote areas) and overcounting (mostly in regional and metropolitan areas) from one census to another (Taylor and Biddle, 2010). However, despite ongoing difficulties, a coherent picture of change in the self-identified Indigenous population does emerge.

Since 1971, the number of individuals identifying in the census as Aboriginal or Torres Strait Islander has increased by almost $300 \%$. At an annual growth rate of $4 \%$ (assuming international migration to be negligible), this is way beyond the bounds of natural increase. The clue to this improbable growth lies in the erratic nature of counts from one census to another (Table 1). Thus, between 1971 and 1976, the Indigenous count increased by 39\%. Over the next intercensal period, the count actually declined slightly, then excessive growth returned between 1981 and 1986 and again between 1991 and 1996. The last two intercensal periods show more reasonable change not dissimilar to underlying rates of natural increase. Given this record, quite what the future holds is one uncertainty that hangs over Indigenous population projections.

The tendency in official statistical reporting in Australia has been to attribute these excessive and fluctuating counts to a variable propensity of Indigenous people to self-identify in census counts (Ross, 1999). A counter-view is that it simply reflects variable census coverage (Gray, 1997; 2002). The first of these is suggestive of behavioural change while the latter alludes more to administrative factors. Either way, explanation has been confounded by a lack of appropriate data, although one set of observations does seem to undermine the proposition that behavioural factors associated with identity are prominent. This stems from a comparison of single year age-specific growth in Indigenous population counts for successive censuses from 1991 to 2001 showing intercensal movements in the distribution of growth that are consistent across the entire age distribution in a way that is simply not compatible with socio-demographic processes (Kinfu and Taylor, 2005). In line with Gray (1997; 2002), what this suggests is variable capture by census enumeration, but a variable capture of whole households rather than of random individuals.

More certain is the fact that the census fails to account for all Indigenous people, far more so than occurs for the rest of the population. Up to the 2006 Census a partial estimate of Indigenous net census undercount was available via the post-enumeration survey. This was partial because the survey sample excluded remote Indigenous communities. What it showed was a fairly steady undercount of around $7 \%$ of the Indigenous population. However, in 2006 the post-enumeration survey was based for the first time on a truly national sample and this revealed a net Indigenous undercount closer to $12 \%$ with even higher rates (around 16\%) in jurisdictions with high proportions of Indigenous population

Table 1 Indigenous census counts, 1971-2006.

\begin{tabular}{|c|c|c|c|c|}
\hline \multirow[t]{2}{*}{ Census year } & \multirow[t]{2}{*}{ Census count } & \multicolumn{3}{|c|}{ Change From Previous Census } \\
\hline & & Number & $\%$ & Annualised \% \\
\hline 1971 & 115953 & & & \\
\hline 1976 & 160915 & 44962 & 38.8 & 6.8 \\
\hline 1981 & 159897 & -1018 & -0.6 & -0.1 \\
\hline 1986 & 227645 & 67748 & 42.4 & 7.3 \\
\hline 1991 & 265459 & 37814 & 16.6 & 3.1 \\
\hline 1996 & 352970 & 87511 & 33.0 & 5.9 \\
\hline 2001 & 410003 & 57033 & 16.2 & 3.0 \\
\hline 2006 & 455031 & 45028 & 11.0 & 2.1 \\
\hline 1971-2006 & $\mathrm{n} / \mathrm{a}$ & 339073 & 292.4 & 4.0 \\
\hline
\end{tabular}

Source: Australian Bureau of Statistics Census of Population and Housing, respective years. 
(notably in Western Australia and the Northern Territory) and relatively low rates elsewhere (ABS, 2008a). Such regional imbalance in census accuracy is a problem when comparing population change between regions and over time and, for this reason, the ABS has calculated post-census ('experimental') estimates of the Indigenous population since 1996.

\section{Population estimates - fit for purpose?}

Indigenous estimates adjust for census undercount and for non-response to the census question on Indigenous status (for a detailed methodology see ABS, 2009b, 53-56). To this extent they seek to standardise for geographic variation in census error. This is important because these estimates are then used as the gold standard for important fiscal purposes, most notably by the Commonwealth Grants Commission in determining disability factors between the states and territories. This idea of generating population statistics that are 'fit for purpose' is considered a central role of the ABS (The Australian Statistician, National Press Club Address, 9 March 2005). Clearly, then, in releasing Indigenous population estimates there is an implicit understanding on the part of the ABS that they are 'fit for purpose'. But are they?

The answer to this question is contingent - if the aim is to establish relativities by comparing jurisdictional populations across Australia then the ABS method of estimation is not only appropriate, it is essential in the sense that such comparison requires the application of a consistent methodology where the estimated parts sum to the whole. To that extent, the overall exercise of fiscal equalisation is probably vindicated. If, however, the aim is to determine local levels of need, for example, in terms of service delivery or workforce planning and for local government grants distribution, then current methods are questionable. Significantly, this is often the level at which Indigenous sociality is constructed (Morphy, 2010a).

For one thing, the calculation of small area (Statistical Local Area) level Indigenous estimates using a top-down pro rata distribution of undercount parameters that are derived for much higher-level geographies does not necessarily provide good estimates at every reduction in scale. Ideally, population modelling should be conducted at the level it is intended to be used (e.g. at shire level). Also, ideally, this should involve the application of local data and intelligence on components of population change. The top-down nature of existing estimation methodology which generates small area estimates from large area parameters is effectively the opposite of this ideal approach.

A second, and related, point is that standard errors for small area level population estimates are not provided and so we have no measure of their reliability. In short, because of the nature of the methodology applied, small area Indigenous estimates appear ill-suited for local/regional needs assessment. Even applying state-level standard errors, they emerge as crude ball-park figures that are difficult to interpret over time. Ultimately, the main route to better Indigenous population estimates for local planning purposes is via improved enumeration and this requires a radical rethink of census field methodology (Morphy, 2007b).

\section{Spatial redistribution}

Notwithstanding the imprecision inherent in census counts and estimates, of all the changes in Indigenous population over the past 200 years or so, none has been more certain nor visible as a measure of colonial impact than the geographic shift in distribution. From an original widespread occupance of the continent with numbers distributed on clan estates at varying densities generally higher along the coast and riverine areas and lower inland (Peterson and Long, 1986; Keen, 2004) - we now see far more clustered residential arrangements that are less determined by connection to traditional clan estates and focused mostly on the suburbs of major cities and regional towns. Over the long term, this reflects the impacts of colonisation leading either to rural-urban migration or to populations in situ being engulfed by expanding urban areas. As we have seen, since 1971, it has also reflected a growing tendency for Indigenous people who were already urban-based to be identified in census counts.

The proportion of the Indigenous population resident in urban areas rose from $44 \%$ in 1971 to $76 \%$ in 2006. Almost one-third of Indigenous Australians are now resident in major cities (Figure 1) and while this remains substantially less than for the total Australian population $(67 \%)$, it nonetheless represents a marked increase from the figure of $15 \%$ recorded for 1971. As this process of ever-greater population counts in urban areas has unfolded, the rural share of the population has continued to decline down from $56 \%$ in 1971 to less than one-quarter in 2001 . 


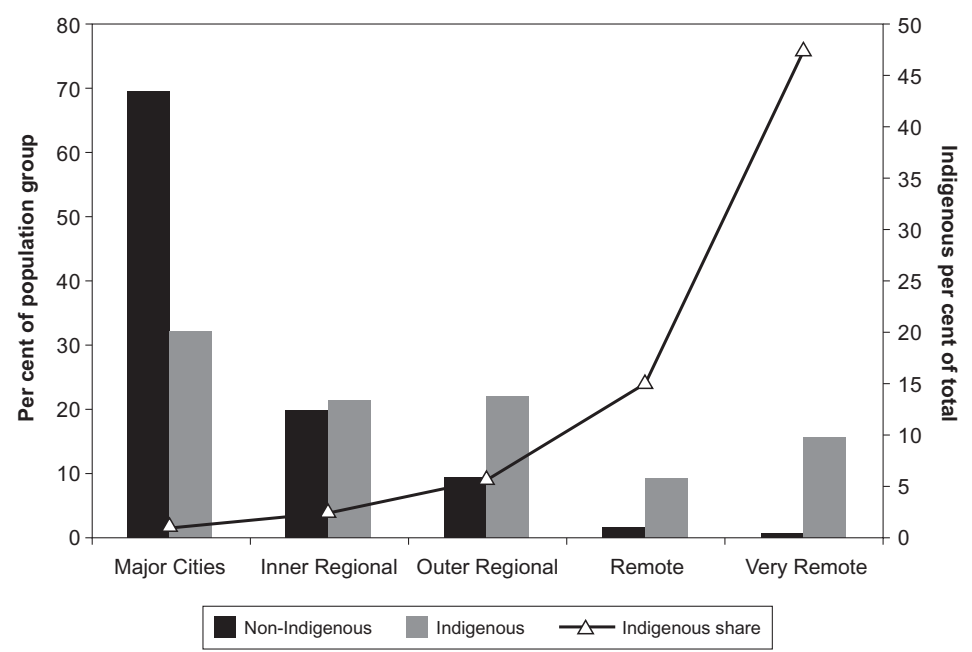

Figure 1 Indigenous and non-Indigenous population distribution by remoteness classification, 2006 (Source: ABS, 2008a, 18).

Despite this shift, the more salient point is that Indigenous people remain far more likely than other Australians to reside away from cities with a much greater tendency to be located in outer regional and remote areas. Partly because of their initial widespread and dispersed spatial distribution, Indigenous Australians encounter the 21st century of global cities and suburban sprawl, of old and new economies and regional adjustment, and of boom and bust resource provinces with a very different spatial history, one in which usurpation by the settler state has been the dominant theme and strategic social actions of Indigenous people have enabled a persistence of customary spatial forms amidst pressures for change (Taylor and Bell, 2004).

In a number of important service towns across regional Australia, especially those that straddle the boundary between remote and regional Australia (e.g. Kalgoorlie, Port Augusta, Broken Hill), Indigenous population growth is outstripping non-Indigenous growth. As a consequence, the Indigenous share of population in these centres is rising. The long-run prospect for such places is towards an increasingly prominent Indigenous profile given differential population dynamics in favour of Indigenous growth - due to positive rather than negative net migration and youthful rather than old age structure (see McGuirk and Argent, 2011). These dynamics have major implications for the nature of services delivered in many regional centres, as well as for the role that Indigenous residents might or should play in terms of their governance and economy. These same demographic trends are leading to an enhanced Indigenous presence at broad regional scales across much of nonmetropolitan Australia. Most notable here is the Murray-Darling Basin where Indigenous people form a sizeable and growing component of the population and where demands for Indigenous engagement in sustainable futures will increase (Taylor and Biddle, 2004).

The term 'remote' Australia draws attention to the vast bulk of the continent where economic development and access to goods and services are severely impeded by small numbers and long distances. It is also that part of Australia where much of the Indigenous estate is re-established under some form of Aboriginal or Torres Strait Islander land title and where new post-productivist mixed economies are emerging (Holmes, 2009). Almost one-third of Indigenous Australians are resident in remote and very remote areas compared with a very small proportion of the rest of the population. In very remote areas (which cover $73 \%$ of the continent), Indigenous peoples constitute almost half of the resident population, although away from the thinly scattered mining and service towns, they are very much the majority. These latter areas have been referred to as an 'Indigenous domain' to reflect spaces where social closure acts as a form of resistance to state dominance (Trigger, 1986) and where Indigenous peoples and their institutions predominate (von Sturmer, 1984, 219). Here the prevailing settlement pattern is one of growing Indigenous towns surrounded by small satellite homeland communities on Indigenous-owned lands that in aggregate 
amount to 1.7 million $\mathrm{km}^{2}$, or $22 \%$ of the continental landmass (see Figure 2; also Altman et al., 2007). This gives Indigenous people an importance in natural resource management and future land and water use that is way beyond their mere numbers a fact that is often overlooked in mainstream debates (Thom and McKenzie 2011).

The effect of this continuity of rural settlement is shown in the varying degrees of Indigenous urbanisation between Australian jurisdictions (Figure 3). In New South Wales and Victoria, where the impact of colonisation has been longest and most comprehensively felt, Indigenous urbanisation rates are well above $80 \%$ and close to non-Indigenous rates. Elsewhere, nonIndigenous urbanisation remains high but Indigenous rates fall away first in Queensland and South Australia and then more noticeably in Western Australia and especially the Northern Territory where most Indigenous people remain in rural areas. The two exceptions are the Australian Capital Territory where, for obvious reasons being a city jurisdiction, Indigenous and nonIndigenous rates are both high, and Tasmania which has the lowest rates of urbanisation overall.

\section{Vulnerable places}

The idea that such workings of political economy might serve to impact negatively on particular population subgroups or sets of locations is emphasised in recent work in spatial analysis that has attempted to 'place' vulnerability by investigating the spatial contexts and ways in which social relations produce 'vulnerable spatialities' (Findlay, 2005; Philo, 2005). The contention here is that Indigenous populations and the spaces they occupy are (almost by definition) vulnerable because, as we have seen, the very notion of indigeneity is relational and socially constructed being dependent on the colonisation of original spaces by invasive, dominant majority populations and cultures. In the past, this worked to enable or deny urban residence, while today the notion of 'remoteness' confers a marginal status on populations who see their personal, cultural,



Figure 2 Discrete ${ }^{1}$ Indigenous communities and the Indigenous estate (Source: After Altman, 2011). 


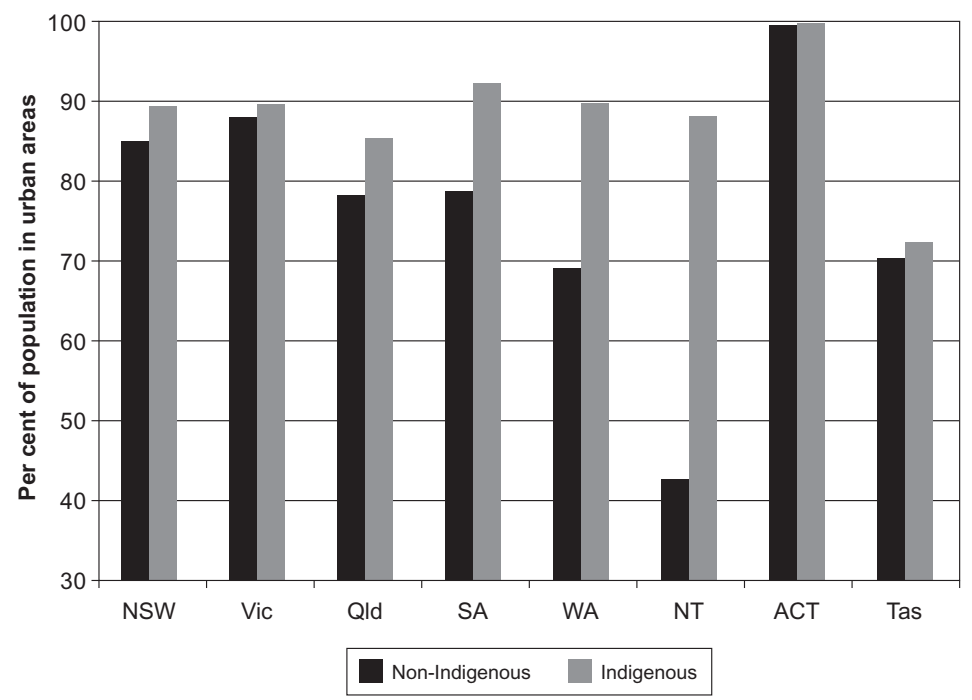

Figure 3 Indigenous and non-Indigenous urbanisation rates by jurisdiction, 2006 (Source: ABS Census of Population and Housing 2006).

and community development inextricably enmeshed in situ in connections to country. From this alternate perspective it is urban areas that are remote! Thus, key causes of spatial vulnerability are inevitably sought in relations of dependency to a regional or national core (Philo, 2005). For Indigenous Australians, this invariably reflects relations with state and federal governments.

To date, Australian geographers have generally mapped vulnerable regions and communities by identifying low or negative employment growth, above average unemployment rates, low labour force participation rates, high housing stress and high concentrations of disadvantaged households (O'Connor et al., 2001; Stimson et al., 2001; Baum et al., 1999; 2005). When applied to remote areas, they have identified mixed but generally favourable outcomes in recent times based on mining, tourism, and service industries. However, as Baum et al. (2008) point out, scale issues involved here can mislead by crowding out more nuanced outcomes - in remote areas what we tend to see is the performance of predominantly nonIndigenous towns as employment sites rather than the plight of particular subgroups. However, more recent work on functional economic regions does identify remote Indigenous communities as a significant cluster (Baum et al., 2008) and this is not surprising. The 1300 or so discrete Indigenous communities that dot remote Australia were established without a modern economic base, nor have they subsequently established one short of a hybrid arrangement characterised by a chronically under-resourced state sector made up mostly of programme funding and transfer payments (Taylor and Stanley, 2005), and limited market and customary sectors (Altman, 2010). This leaves them highly vulnerable to shifts in government policy and brings into sharp relief a range of policy tensions around the nature and meaning of Indigenous people's development in contemporary Australia (Vanstone, 2005; Altman et al., 2007; Altman, 2010).

\section{Limits to spatial diversity}

Implicit in current policy settings aimed at closing the gaps in socioeconomic status is a notion of corresponding spatial convergence. This 'places' urban locations on one side of the policy discourse as desirable locations and implies a shift to the left in the Indigenous population shares shown in Figure 1 if such policies are effective. The fact is, such a shift has been underway for some time partly because inter-regional net migration as indicated in Figure 4, although it has to be said that natural increase is the main contributor to urban growth and this is enhanced by high rates of partnering between Indigenous men and nonIndigenous women in metropolitan areas and large regional towns. In the early part of the contemporary period, governments supported remote settlement and spatial diversity (Commonwealth of Australia, 1987) now this is less 


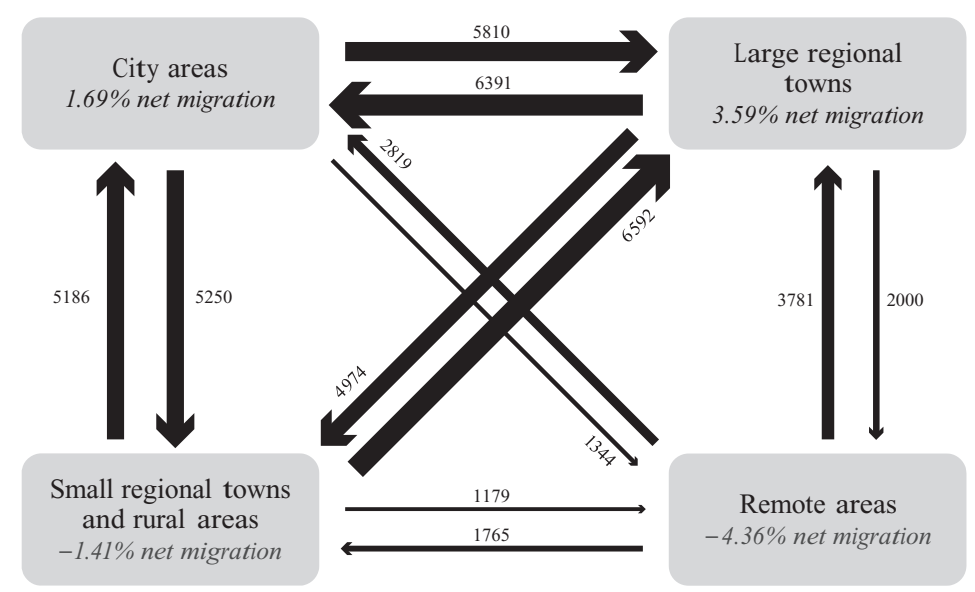

Figure 4 Size and direction of Indigenous inter-regional migration flows, 2001-2006 (Source: Adapted from Biddle 2009, 11).

certain. Why should this be so? The answer is found in recent analysis of competing principles in Indigenous affairs.

Sanders (2008; 2009) identifies a paradigm shift in recent years involving a movement away from notions of choice and diversity and back towards earlier-held ideas of guardianship based on a conviction that governments can, and should (in order to achieve equality goals), intervene to shape and enhance Indigenous participation and life circumstances. Accompanying this shift to what Sanders (2009) calls the 'directive right' of politics, there has also been a resurgence of neo-liberal thinking in which government support for remote Indigenous settlement is seen as contributing to a social pathology that only unhindered market engagement involving labour mobility can resolve. Not surprisingly, this discourse has generated discussion regarding the viability of remote Indigenous settlements and the appropriate spatial options for Indigenous people if government goals are to be realised (Vanstone, 2005; Johns, 2009).

According to Sanders (2009), such ideas stem from the (inevitably) cross-cultural nature of Indigenous affairs policy-making and associated ideas of policy failure that have become a keynote feature in recent years. Because Indigenous life practices and aspirations can be very different from those of the mainstream, government programmes seldom, if ever, work as intended. What eventuates on the ground is heavily mediated by Indigenous agency and the results of government intervention are often a long way from programme design (Sanders, 2009).
One consequence of this is a gradual loss of belief on the part of policy practitioners and planners that their approach to Indigenous affairs is actually working. Indeed, with time and lack of progress, a discourse of failure begins to accumulate such that the old ways become to be seen as part of the problem. Over the past few years, we have seen one such period of self-doubt leading to considerable upheaval in fundamental policy settings and a direct line to the vulnerable position that many remote outstation residents now find themselves in.

In line with this shift, the signal now from government to Indigenous Australians, and especially to those in remote areas, is to eschew the politics and possibilities of difference in order to embrace the institutions of mainstream Australian life with migration-inducing implications. Transmission of this signal is via the policy process with emphasis placed on pursuing market engagement through programmes to enhance labour mobility, welfare to work reform, and more individualised, as opposed to communal, articulation with government services. Of particular note is the lifting of remote area exemptions for the unemployed combined with dismantlement of the Community Development Employment Projects (CDEP) scheme that has long provided an economic underpinning for remote settlement. Also significant is a freeze on expenditure at outstations and a concentration of investment in 29 growth towns or hubs (COAG, 2009). In terms of regional planning, this is classic growth pole strategy based on implied cumulative causation. Put simply, there is an assessment by the state that life chances will be 
improved by a redistribution of Indigenous people into fewer larger locations that have more services and mainstream opportunities. One factor that has stimulated this assessment is the weight of population momentum implied by Indigenous age distribution.

\section{Population composition}

The aspect of demography that almost defines the Indigenous population is age structure. Because of sustained high adult mortality, a belated decline in Indigenous women's fertility and an augmentation of Indigenous births due to Indigenous male exogamy, the age profile of the Indigenous population is overwhelmingly youthful and quite the inverse of the general situation (Figure 5). As a consequence, an Indigenous inter-generational report would read quite differently from those recently released by the Federal Treasury (Commonwealth of Australia, 2002; 2004; 2009). In effect, while the nation as a whole is increasingly focused on the means to finance and service retirees and the aged, Indigenous people barely reach retirement age. Their concerns are more firmly fixed at the opposite end of the social policy spectrum to do with child and family health, housing for new family formation, education, training, youth, criminal justice, employment, and the means to secure asset accumulation and sustainable livelihoods.

While demographic change is an inevitable cause and effect of social and economic transformation among Indigenous Australians, the interactions and consequences involved are often lost in policy debate given the gradual, almost imperceptible, pace at which demographic processes unfold compared with the political imperative and immediacy of addressing community needs. However, the point is not entirely lost. For some time now researchers have revealed a need for Indigenous economic participation and productivity to keep pace with an expanding working-age population (Taylor and Hunter, 1998; Hunter and Taylor, 2004; Biddle et al., 2009), while (some) policy-makers recognise the potential for a decline in employment outcomes that this relationship implies (Ah Kit, 2004).

It is therefore noteworthy that the intergenerational reports produced to date have overlooked the very different challenges that arise for Indigenous people as a consequence of demographic processes. In particular, it should be noted that ageing is also a feature of the Indigenous population - it is just temporally lagged in its effect with consequently different policy implications. Almost universally across the country, Indigenous populations are moving into a phase of demographic transition due to reduced fertility and increased survival that will see the population in the prime workforce age groups peak, a process that is prolonged by movement towards demographic convergence (Biddle and Taylor, 2009). As a consequence, the ratio of age groups dependent on those of working age (for income) will be minimised. Assuming this ageing process will continue apace, the structural moment will eventually pass, obviously at different times in

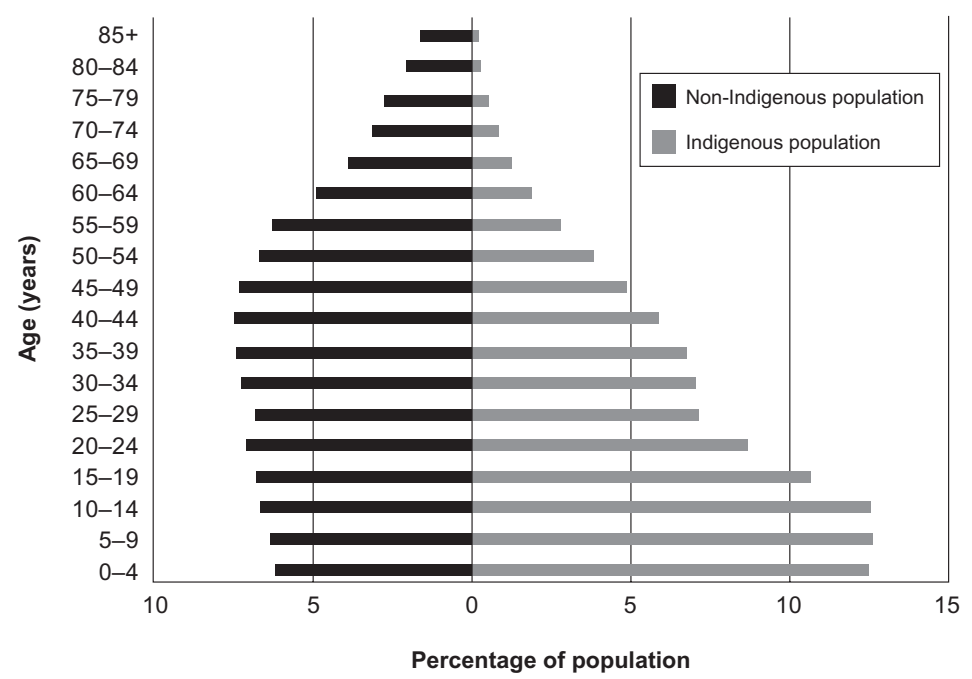

Figure 5 Age distribution of Indigenous and non-Indigenous Australians, 2006. (Source: ABS, 2009c, 26-28). 
different places, but generally over the next few decades (Biddle and Taylor, 2009).

While the general contours of this demographic transition are reasonably well established what is lacking is a clear sense of the practical implications at varying scales. In one of the few examples at the national level, Jackson (2008, 225 ) has poignantly noted in regard to the nonIndigenous population that it became educated before it became 'old' and that the risk now for Indigenous Australians is that they will become 'old' before they are educated. The consequences of such a discrepancy are already felt in the relativities of economic participation and productivity that stimulate so much of the national policy agenda towards 'closing the gap'. The longerterm consequences are related to the so-called 'demographic dividend' - that period in demographic transition outlined above where the minimising of age-dependency ratios enables the maximising of income, savings and investments, at least potentially (Bloom and Williamson, 1998). Given current levels of Indigenous education, workforce participation and productivity the danger is that the opportunity for Indigenous families and communities to 'cash in' on this transitory structural position may be foregone, or at least less than optimised, for want of adequate human capital among key implicated cohorts. While this dynamic is easily grasped conceptually, we have little appreciation in a practical sense of how it is unfolding on the ground in individual communities and at scales that reflect the local impact of collective decisions regarding social change. Taylor (2010) provides one exception by identifying diminishing rates of school attendance in one Aboriginal town (Wadeye) against a background of rapidly expanding working-age population.

\section{Future population}

The first projections of Indigenous population were prepared for the Royal Commission into Aboriginal Deaths in Custody in 1990 (Gray and Tesfaghiorghis, 1991) and subsequent efforts have been summarised by Wilson (2009). Initially, official ABS projections were only available at national, state and territory level and only for a 10 year period (ABS, 1998); however, these are now available for a 20 year period (2001 to 2021) and for 37 Indigenous regions, although in the latter case not by age and sex (ABS, 2009a). There have been other attempts to derive estimates for more detailed geographies, such as the recent projections for regions of New South Wales (Khalidi, 2008) and for customised regions including the Australian desert (Brown et al., 2008) and Cape York Peninsula (Taylor and Bell, 2002), as well as for longer time frames out to 2031 (Biddle and Taylor, 2009) and 2051 (Productivity Commission, 2005). Policy-wise, projections have been successfully deployed in the development of Indigenous employment policy (Taylor and Hunter, 1998), in regional needs assessment for service delivery (Taylor, 2004), and in driving home the fiscal opportunity-cost message that business as usual in Indigenous affairs is not a rational option due to the weight of population momentum (Hunter and Taylor, 2002).

As mentioned earlier, large variations in base year census counts are one reason why there is serious doubt over the reliability of Indigenous projections, more so than is normally the case. This is even the case over the short term as Table 2 demonstrates. Early attempts at projection in the 1980s appear to have been thwarted by the unanticipated rise in population counts in the 1990s. Subsequent efforts by the ABS seem to be

Table 2 Forecast accuracy: ratios of national Indigenous population projections to observed census-based estimates: 1991-2006.

\begin{tabular}{|llll|}
\hline Projection series & \multicolumn{3}{c|}{ Census Year } \\
\cline { 2 - 4 } & 1991 & \multirow{3}{*}{2096} & 2001 \\
\hline Gray \& Tesfaghiorghis (1986 based) & 0.72 & 0.71 & 0.66 \\
ABS low series (1996 based) & & 0.93 & 0.91 \\
ABS high series (1996 based) & & 1.10 & 1.26 \\
ABS low series (2001 based) & & 0.97 \\
ABS high series (2001 based) & & 1.05 \\
\hline
\end{tabular}

Source: Gray and Tesfaghiorghis (1991) and ABS various.

ABS, Australian Bureau of Statistics. 
closer to the mark but there remains a substantial gap between low and high series. The former models change based on demographic factors alone and tends to underestimate, the latter assumes additional non-demographic increase and tends to overestimate.

With this uncertainty in mind, current forecasts indicate a steady rise in the Indigenous population with average annual growth rates above the national average. The latest ABS projections assume this average rate to be almost twice that of the total population over the medium term to 2021 (ABS, 2009a, 34). As a consequence, the Indigenous population will continue to rise as a share of the Australian population with one projection pointing to an increase from $2.5 \%$ at present to $3.2 \%$ by 2031 (Biddle and Taylor, 2009). Indications are that Indigenous people will remain a minority population in major cities while elsewhere their relative presence will loom larger and larger with increased distance from cities. By 2031, it is likely that Indigenous people will be the majority in very remote areas.

However, in terms of absolute numbers the main growth of Indigenous population is forecast to be in major cities and in urban areas generally. This results from a combination of net migration gains in most cities (except Sydney and Melbourne) and natural increase in situ. The latter is augmented in cities more than elsewhere by births of Indigenous children to non-Indigenous mothers and Indigenous fathers. Some idea of the impact of this increase in city numbers is provided by the fact that the combined Indigenous population of Brisbane and Sydney will almost double from 93000 in 2006 to 170000 by 2031 even without accounting for any net migration gain (Biddle and Taylor, 2009). As we have seen the Indigenous population of Australia is already highly urbanised (76\%) and is one of the most urbanised Indigenous populations in the world. While this is set to increase, Indigenous people will remain more widely dispersed than the population as a whole ranging from inner metropolitan suburbs to the remotest parts of the continent. This produces an unusually diverse range of residential circumstances and variable opportunities and constraints for social and economic participation.

\section{Conclusion}

From the point of view of geographic analysis, Australian postcolonial demography is an impor- tant by-product of constitutional amendment. It provides, for the first time, a consistent basis upon which to chart contemporary growth and change in a self-identified Indigenous population, albeit within the constraints imposed by administrative process. It also provides the means to establish parameters for estimating the impact of these dynamics into the future. More than two centuries on from initial colonisation, this shows that descendants of the first Australians have arrived at a significant demographic moment. Likely restored in original numbers, but certainly far more youthful in profile, the $21 \mathrm{st}$ century population profile will be marked by continued population momentum and further urbanisation. At the same time, connections to country that are increasingly enabled by various forms of land rights determination will ensure that the population remains widely dispersed relative to most Australians.

This particular construction of population geography is simultaneously both instructive and misleading as an indicator of the contemporary condition of Indigenous peoples. On the one hand, it is well suited to the efficient provision of citizen rights (Rowse, 2009; Taylor, 2009) because it establishes a basis for benchmarking as the primary means of measuring the efficacy of government policy in the area of Indigenous affairs (SCRGSP, 2009). Presently, this is conducted as a gap analysis that is informed by a demography of disadvantage (Jones, 2004) in which indigeneity is considered a highly predictive spatial variable to the point where it used as such in indices of advantage and disadvantage (ABS, 2008b). To this extent, both demographic and spatial convergence are implied as logical aims. On the other hand, it fails to provide for Indigenous 'peoples' interests in inherent and proprietary rights that are manifest in the many forms of native title settlement and agreementmaking that increasingly exist for incorporated land-holding groups (Tehan et al., 2006). Nor does it reflect the widespread and associated configurations of post-classical Indigenous social organisation that Sutton (2003, 209-211) refers to as 'families of polity'. These he identifies as cognatic descent groups that 'form major structural elements of public life in Aboriginal society' and that are of 'enduring and central importance to the conduct of Aboriginal business' (Sutton 2003: 210). They enable larger groupings into tribal units or language groups and one current manifestation is evident in the extent of application for native title determina- 
tion. As such, they provide the means by which Indigenous peoples express collective identities and seek to negotiate for their needs and aspirations including fundamental issues of recognition, inclusion and economic opportunity (Tehan et al., 2006, 3). Interestingly, the 2008 National Aboriginal and Torres Strait Islander Social Survey indicated that fully $62 \%$ of the Indigenous population identified with a clan or language group, a figure that was markedly up from 53\% in the equivalent 2002 survey. In effect, the Indigenous cultural map is vastly different from that imposed by the ABS (Arthur and Morphy, 2005) and formal statistical geographies are unlikely to provide a demography of Indigenous polities that have rights and interests in particular places.

While a role remains for postcolonial demography (Rowse, 2009), the challenge for social science and for public debate is to move beyond conventional classification and recognise more ethnographically informed geographies of Indigenous peoples that are reflective of the demand for customised statistics now being expressed by representative groups such as the Anindilyakwa Land Council, Thamarrurr Incorporated, Fitzroy Futures Forum, Nyamba Buru Yawuru Ltd, Mirriuwung-Gajerong Corporation, and the Murray Lower Darling Rivers Indigenous Nations, to name just a few. All of these entities are now institutional players who seek to establish their own representations of sociality, including that of diaspora, and they see opportunities and constraints in pursuit of goals that they are beginning to define and that can be quite different from those determined by governments. In the post-land rights development era, the problem for Indigenous leaders is not a failure to recognise predicament, it is a need for support in charting self-determined ways out of it. Consistent with articles 18, 19, and 23 of the United Nations Declaration on the Rights of Indigenous Peoples (United Nations, 2008), and in line with emerging practice (Pereira et al., 2009; Walling et al., 2009; Morphy, 2010b), this requires a decolonisation of information processes (Shaw et al., 2006).

\section{NOTE}

1. Discrete Indigenous communities are defined by the Australian Bureau of Statistics as, 'a geographic location, bounded by physical or cadastral (legal) boundaries, and inhabited or intended to be inhabited predominantly by Indigenous people, with housing or infrastructure that is either owned or managed on a community basis' (ABS, 2002).

\section{REFERENCES}

ABS, 1998: Experimental Projections of the Aboriginal and Torres Strait Islander Population, 1996 to 2006, Cat. No. 3231.0, ABS, Canberra.

Ah Kit, J., 2004: Why do we always plan for the past? Engaging Aboriginal people in regional development. Paper presented at the Sustainable Economic Growth for Regional Australia (SEGRA) 8th National Conference, Alice Springs, 7th September, 2004.

Altman, J.C., 2010: What future for remote Indigenous Australia? Economic hybridity and the neoliberal turn. In Altman, J.C. and Hinkson, M. (eds) Culture Crisis: Anthropology and Politics in Aboriginal Australia. UNSW Press, Sydney, 259-281.

Altman, J.C., 2011: Diritti fondiari indigeni e sviluppo' [Indigenous land rights and development]. Dialoghi Internazionali - Città nel mondo 14, 93-107.

Altman, J.C., Buchanan, G. and Larsen, L., 2007: The environmental significance of the Indigenous estate: natural resource management as economic development in remote Australia. CAEPR Discussion Paper No. 286, Centre for Aboriginal Economic Policy Research, The Australian National University, Canberra.

Arthur, W. and Morphy, F. (eds), 2005: Macquarie Atlas of Indigenous Australia: Culture and Society Through Space and Time. The Macquarie Library Pty Ltd, Sydney.

Australian Bureau of Statistics (ABS), 2002: Housing and Infrastructure in Aboriginal and Torres Strait Islander Communities, Australia, 2001, Cat No. 4710.0, ABS, Canberra.

Australian Bureau of Statistics (ABS), 2007: ABS Directions in Aboriginal and Torres Strait Islander Statistics, Cat No. 4700.0, ABS, Canberra.

Australian Bureau of Statistics (ABS), 2008a: Population Characteristics, Aboriginal and Torres Strait Islander Australians 2006, Cat. No. 4713.0, ABS, Canberra.

Australian Bureau of Statistics (ABS), 2008b: Information Paper: An Introduction to Socio-Economic Indexes for Areas (SEIFA), 2006. Cat. No. 2039.0, ABS, Canberra.

Australian Bureau of Statistics (ABS), 2009a: Experimental Estimates and Projections, Aboriginal and Torres Strait Islander Australians, 1991 to 2021, Cat. No. 3238.0, ABS, Canberra.

Australian Bureau of Statistics (ABS), 2009b: Population Estimates: Concepts, Sources and Methods, Cat. No. 3228.0.55.001, ABS, Canberra.

Australian Bureau of Statistics (ABS), 2009c: Australian Demographic Statistics, June Quarter 2009, Cat. No. 3101.0, ABS, Canberra.

Baum, S., Stimson, R., O'Connor, K., Mullins, P. and Davis, R., 1999: Community Opportunity and Vulnerability in Australia's Cities and Towns: Characteristics, Patters and Implications. University of Queensland Press, for the Australian Housing and Urban Research Institute, Brisbane.

Baum, S., O'Connor, K. and Stimson, R., 2005: Fault Lines Exposed: Advantage and Disadvantage across Australia's Settlement System. Monash University e-Press, Melbourne.

Baum, S., Mitchell, W. and Han, J.H., 2008: Socio-economic performance across Australia's non-metropolitan functional economic regions. Australasian Journal of Regional Studies 14, 215-249.

Biddle, N., 2009: The geography and demography of Indigenous migration: insights for policy and planning. CAEPR Working Paper No. 58, Centre for Aboriginal Economic Policy Research, The Australian National University, Canberra. 
Biddle, N. and Taylor, J., 2009: Indigenous population projections, 2006-2031: planning for growth. CAEPR Working Paper No. 56, Centre for Aboriginal Economic Policy Research, The Australian National University, Canberra.

Biddle, N., Taylor, J. and Yap, M., 2009: Are the gaps closing? Regional trends and forecasts of Indigenous employment. Australian Journal of Labour Economics 12, 263-281.

Bloom, D.E. and Williamson, J.G., 1998: Demographic transitions and economic miracles in emerging Asia. World Bank Economic Review 12, 419-465.

Brown, D., Taylor, J. and Bell, M., 2008: The demography of desert Australia. The Rangeland Journal 30, 29-43.

Buckmaster, L. and Thomas, M., 2009: Social Inclusion and Social Citizenship: Towards a Truly Inclusive Society, Parliamentary Library Research Paper 23, October 2009, no. 8, 2009-10: 12. Retrieved: 14 January 2011 from <http:// www.aph.gov.au/library>.

Commonwealth Bureau of Census and Statistics, 1973: The Aboriginal population. Bulletin 9, Census of Population and Housing, 30 June 1971, Commonwealth Bureau of Census and Statistics, Canberra.

Commonwealth of Australia, 1987: Return to Country: The Aboriginal Homelands Movement in Australia, Report of the House of Representatives Standing Committee on Aboriginal Affairs, Australian Government Publishing Service, Canberra.

Commonwealth of Australia, 2002: Intergenerational Report 2002-03, 2002-03 Budget Paper No. 5, Circulated by the Honourable Peter Costello, M.P., Treasurer of the Commonwealth of Australia, For the Information of Honourable Members on the Occasion of the Budget 2002-03, 14th May 2002, Parliament House, Canberra.

Commonwealth of Australia, 2004: Australia's Demographic Challenges. Department of the Treasury, Canberra.

Commonwealth of Australia, 2009: Australia's Demographic Challenges. Department of the Treasury, Canberra.

Council of Australian Governments (COAG), 2009: National Partnership Agreement on Remote Service Delivery. COAG, Canberra.

Cunningham, J., 1998: Implications of changing Indigenous population estimates for monitoring health trends. Australasian Epidemiologist 5, 6-8.

Dodson, M., 1994: The Wentworth lecture: the end in the beginning: re(de)fining Aboriginality. Australian Aboriginal Studies 1994, 2-13.

Findlay, A., 2005: Editorial: vulnerable spatialities. Population Space and Place 11, 429-439.

Gray, A., 1997: The explosion of aboriginality: components of indigenous population growth 1991-96. CAEPR Discussion Paper No. 142, Canberra: Centre for Aboriginal Economic Policy Research, The Australian National University.

Gray, A., 2002: The future history of Aboriginal families. In Briscoe, G. and Smith, L. (eds) The Aboriginal Population Revisited: 70,000 Years to the Present. Aboriginal History Monograph 10, ANU Printing, Canberra, 109-132.

Gray, A. and Tesfaghiorghis, H., 1991: Social indicators of the Aboriginal population of Australia. CAEPR Discussion Paper No. 18, CAEPR, ANU, Canberra.

Hill, K., Barker, B. and Vos, T., 2007: Excess Indigenous mortality: Are Indigenous Australians more severely disadvantaged than other Indigenous populations? International Journal of Epidemiology 36, 580-589.

Holmes, J., 2009: The multifunctional transition in Australia's tropical savannas: the emergence of consumption, protection and Indigenous values. Geographical Research 48, 342-358.

Hunter, B.H. and Taylor, J., 2002: An overview of the costs of indigenous unemployment. In Saunders, P. and Taylor, R. (eds) The Price of Prosperity: The Economic and Social Costs of Unemployment. UNSW Press, Sydney, 109-134.

Hunter, B.H. and Taylor, J., 2004: Indigenous employment forecasts: Implications for reconciliation. Agenda 11, 179 192.

Jackson, N., 2008: Educational attainment and the (growing) importance of age structure: Indigenous and nonIndigenous Australians. Journal of Population Research 25, 223-242.

Johns, G., 2009: No Job No House: An Economically Strategic Approach to Remote Aboriginal Housing. The Menzies Research Centre, Canberra.

Jones, G., 2004: The demography of disadvantage. Journal of Population Research 21, 107-126.

Keen, I., 2004: Aboriginal Economy and Society: Australia at the Threshold of Colonisation. Oxford University Press, Oxford.

Khalidi, N., 2008: Indigenous Indicative Population Projections NSW: 2006 to 2021. New South Wales Aboriginal Housing Office, Sydney.

Kinfu, Y. and Taylor, J., 2005: On the components of Indigenous population change. Australian Geographer 36, 233 255.

Kowal, E., 2010: Is culture the problem or the solution? Outstation health and the politics of remoteness. In Altman, J.C. and Hinkson, M. (eds) Culture Crisis: Anthropology and Politics in Aboriginal Australia. UNSW Press, Sydney, 179-195.

Kukutai, T., 2004: The problem of defining an ethnic group for public policy: who is Maori and why does it matter? Social Policy Journal of New Zealand 23, 86-108.

M-Guirk, P. and Argent, N., 2011: Population growth and change: implications for Australia's cities and regions. Geographical Research 49, 317-335.

Morphy, F., 2007a: Uncontained subjects: 'population' and 'household' in remote Aboriginal Australia. Journal of Population Research 24, 163-184.

Morphy, F. (ed.), 2007b: Agency, Contingency and Census Process: Observations of the 2006 Indigenous Enumeration Strategy in Remote Aboriginal Australia. ANU E Press, Canberra.

Morphy, F., 2010a: (Im)mobility: regional population structures in Aboriginal Australia. Australian Journal of Social Issues 45, 363-382.

Morphy, F., 2010b: Population, people and place: The Fitzroy Valley Population Project. CAEPR Working Paper No. 70 , Centre for Aboriginal Economic Policy Research, The Australian National University, Canberra.

Mulvaney, J., 2002: Difficult to found an opinion: 1788 Aboriginal population estimates. In Briscoe, G. and Smith, L. (eds) The Aboriginal Population Revisited: 70,000 Years to the Present. Aboriginal History Monograph 10, ANU Printing, Canberra, 1-9.

Niezen, R., 2003: The Origins of Indigenism: Human Rights and the Politics of Identity. University of California Press, Berkeley.

O'Connor, K., Stimson, R. and Daly, M., 2001: Australia's Changing Economic Geography: A Society Dividing. Oxford University Press, Melbourne.

Passel, J.S., 1996: The growing American Indian population, 1969-1990: beyond demography. In Sandefur, G.D., Rindfuss, R.R. and Cohen, B. (eds) Changing Numbers, Changing Needs: American Indian Demography and 
Public Health. National Academy Press, Washington D.C, 79-103.

Pereira, N., de, O.M., Santos, R.V., Welch, J.R., Souza, L.G. and Coimbra, C.E.A. Jr., 2009: Demography, territory and identity of Indigenous peoples in Brazil: the Xavante Indians and the 2000 Brazilian census. Human Organization 68, 166-180.

Peterson, N. and Long, J., 1986: Australian Territorial Organization: A Band Perspective. Oceania Monographs, University of Sydney, Sydney.

Phillip, A., 1787: Governor Phillip's instructions 25 April 1787. Resource document. National Archives of Australia. (www document). Retrieved: 6 December 2010 from <http://www.foundingdocs.gov.au/resources/transcripts/ nsw2_doc_1787.pdf>.

Philo, C., 2005: The geographies that wound. Population Space and Place 11, 441-454.

Productivity Commission, 2005: Economic Implications of an Ageing Australia. Productivity Commission Technical Papers, Productivity Commission, Melbourne.

Prout, S., 2009: Vacuums and veils: engaging with statistically 'invisible' Indigenous population dynamics in Yamatji Country, Western Australia. Geographical Research 47, 408-421.

Ross, K., 1999: Population issues, Indigenous Australians. Cat. No. 4708.0, ABS, Canberra.

Rowse, T., 2006: Towards a history of Indigenous statistics in Australia. In Hunter, B. (ed.) Assessing the Evidence on Indigenous Socioeconomic Outcomes: A Focus on the 2002 NATSISS. ANU E Press, Canberra, 1-11.

Rowse, T., 2009: Official statistics and the contemporary politics of indigeneity. Australian Journal of Political Science 44, 193-211.

Sanders, W., 2008: In the name of failure: A generational revolution in Indigenous affairs. In Aulich, C. and Wettenhall, R. (eds) The Fourth Howard Government. UNSW Press, Sydney, 187-205.

Sanders, W., 2009: Ideology, evidence and competing principles in Australian Indigenous affairs: from Brough to Rudd via Pearson and the NTER. CAEPR Discussion Paper No. 289, Centre for Aboriginal Economic Policy Research, The Australian National University, Canberra.

Shaw, W.S., Herman, R.D.K. and Dobbs, G.R., 2006: Encountering indigeneity: re-imaging and decolonizing geography. Geografiska Annaler 88 B, 267-276.

Smith, L.R., 1980: The Aboriginal Population of Australia. Australian National University Press, Canberra.

Smith, L.R., McCalman, J., Anderson, I., Smith, S., Evans, J. and McCarthy, G., forthcoming: Fractional identities: the political arithmetic of Aboriginal Victorians. In Axelsson, P. and Sköld, P. (eds) Indigenous Peoples and Demography: The Complex Relation Between Identity and Statistics. Berghahn Books, Oxford.

Steering Committee for the Review of Government Service Provision (SCRGSP), 2009: Overcoming Indigenous Disadvantage: Key Indicators 2009. Productivity Commission, Canberra.

Stimson, R., Baum, S., Mullins, P. and O'Connor, K., 2001: Australia's regional cities and towns: modeling community opportunity and vulnerability. Australasian Journal of Regional Studies 7, 23-62.

von Sturmer, J., 1984: Aborigines and Uranium: Consolidated Report. Australian Institute of Aboriginal Studies, Canberra.

Sutton, P., 2003: Native Title in Australia: An Ethnographic Perspective. Cambridge University Press, Cambridge.
Taylor, J., 2004: Social Indicators for Aboriginal Governance: Insights from the Thamarrurr Region, Northern Territory. ANU E Press, Canberra.

Taylor, J., 2008: Indigenous peoples and indicators of wellbeing: Australian perspectives on United Nations global frameworks. Social Indicators Research 87, 111-126.

Taylor, J., 2009: Indigenous demography and public policy in Australia: population or peoples? Journal of Population Research 26, 115-130.

Taylor, J., 2010: Demography as destiny: schooling, work and Aboriginal population change at Wadeye. CAEPR Working Paper No. 64, Centre for Aboriginal Economic Policy Research, The Australian National University, Canberra.

Taylor, J. and Bell, M., 2002: The Indigenous population of Cape York Peninsula, 2001-2016. CAEPR Discussion Paper No. 227, Centre for Aboriginal Economic Research, The Australian National University, Canberra.

Taylor, J. and Bell, M., 2004: Continuity and change in Indigenous Australian population mobility. In Taylor, J. and Bell, M. (eds) Population Mobility and Indigenous Peoples in Australasia and North America. Routledge, London and New York, 13-44.

Taylor, J. and Biddle, N., 2004: Indigenous people in the Murray-Darling Basin: A statistical profile. CAEPR Discussion Paper No. 264, Centre for Aboriginal Economic Policy Research, The Australian National University, Canberra.

Taylor, J. and Biddle, N., 2010: Estimating the accuracy of geographic variations in Indigenous population counts. Australian Geographer 41, 469-485.

Taylor, J. and Hunter, B., 1998: The Job Still Ahead: Economic Costs of Continuing Indigenous Employment Dis parity. Aboriginal and Torres Strait Islander Commission, Canberra.

Taylor, J. and Stanley, O., 2005: Opportunity costs of the status quo in the Thamarrurr Region, Northern Territory. CAEPR Working Paper No. 28, Centre for Aboriginal Economic Policy Research, The Australian National University, Canberra.

Tehan, M., Palmer, L., Langton, M. and Mazel, O., 2006 Sharing land and resources: modern agreements and treaties with Indigenous people in settler states. In Langton, M., Mazel, O., Palmer, L., Shain, L.K. and Tehan, M. (eds) Settling With Indigenous People. The Federation Press, Sydney, 1-19.

Thom, B. and McKenzie, F., 2011: The Population Policy Debate from a Natural Resource Perspective: Reflections from the Wentworth Group. Geographical Research 49, 348-361.

Trigger, D.S., 1986: Blackfellas and whitefellas: the concepts of domain and social closure in the analysis of racerelations. Mankind 16, 99-117.

United Nations, 2008: United Nations Declaration on the Rights of Indigenous Peoples, General Assembly Resolution 61/295, 13 September 2007, United Nations, New York.

Vanstone, A., 2005: Beyond conspicuous compassion. Address to the Australia and New Zealand School of Government, The Australian National University, Canberra, December 2005.

Walling, J., Small-Rodriguez, D. and Kukutai, T., 2009: Tallying tribes: Waikato-Tainui in the Census and Iwi Register. Social Policy Journal of New Zealand 36, 2-15.

Wilson, T., 2009: A multistate model for projecting regional populations by Indigenous status: an application to the Northern Territory, Australia. Environment and Planning A 41, 230-249. 